\title{
El desenlace con bodas en las Novelas de Miguel de Cervantes: el ejemplo de La Gitanilla para el matrimonio feliz en las Novelas de María de Zayas*
}

Rosangela Schardong ${ }^{a}$

* El estudio aquí presentado amplía y $\quad \mathrm{rofundiza}$ considerablemente el artículo "El matrimonio en las novelas de Miguel de Cervantes y María de Zayas", que fue leído en el XVIII Congreso de la Asociación Internacional de Hispanistas, realizado en julio de 2013, en Buenos Aires, Argentina.

\begin{abstract}
Resumen
En siete de las doce Novelas ejemplares (1613), de Miguel de Cervantes, la celebración del matrimonio representa el desenlace feliz. La superación de distintos trabajos y contiendas lleva a uno o múltiples enlaces. Aunque en cada trama el casamiento tenga su particular significado, siempre asegura la ejemplaridad de la fábula. Merece relieve que el matrimonio como signo de desenlace venturoso tiene otros matices en las Novelas amorosas y ejemplares (1637), de María de Zayas. El artículo analiza y compara los elementos que configuran la ejemplaridad del matrimonio en la obra de ambos novelistas. El análisis indica como María de Zayas rechaza algunas prácticas encontradas en las novelas cervantinas que configuran el final feliz con matrimonio para dar mayor autonomía a los cónyuges y restar la autoridad paterna. El estudio comparativo concluye que Zayas, posiblemente inspirada en las reivindicaciones de la Gitanilla, en sus Novelas altera significativamente las acostumbradas fórmulas de desenlace con bodas al plantear un conjunto de criterios prenupciales que llevan a sus protagonistas femeninas al matrimonio feliz.
\end{abstract}

Palabras-clave: Novela corta; Matrimonio; Ejemplaridad; Desenlace; Costumbres. 
En las letras españolas de los siglos XVI y XVII el desenlace formaba parte de las normas en uso que constituían los distintos géneros del arte poético. Del mismo modo que la Poética de Aristóteles señala que el final catastrófico de las tragedias de Eurípides "es correcto", puesto que sus piezas son consideradas "las más trágicas" (XIII, 2009, p. 66), en la efervescencia artística del Siglo de Oro español las poéticas vernáculas y el modelo de las autoridades regulan el paradigma de la trama y del desenlace de los nuevos géneros que van surgiendo, como son, por ejemplo, la novela amorosa de aventuras ${ }^{1}$, la novela pastoril, la picaresca y la tragicomedia.

Miguel de Cervantes ensancha la contribución a las letras áureas con sus Novelas ejemplares (1613), que inauguran el género novela corta española. Atento a las normas del arte de su tiempo, Cervantes introduce innovaciones a las técnicas de novelar sin prescindir de la verosimilitud, la admiración y la ejemplaridad, principios estimados por las autoridades literarias del período, como por ejemplo López Pinciano, en su Philosophía Antigua Poética (1596). ${ }^{2}$

En ese tratado de arte poético, Pinciano condiciona las cualidades de la fábula a tres pares de contrarios: "la fábula deue ser: vna y varia, perturbadora y quietadora de los ánimos, y admirable y verisímil" (Ep. 5a , 1973, p. 39). La unidad dice respecto a la acción, a la persona y al tiempo (Ep. 5a, p. 3952), mientras que la variedad se extiende, además de a estos requisitos, a la locución y a la materia (Ep. $5^{a}$, p. 39, 53, 58). Para incitar a seguir la virtud y evitar el vicio, la fábula debe mover los afectos, eso es, el ánimo del lector o espectador. Pinciano traslada el clásico precepto de movere al de perturbar cuando define que

${ }^{1}$ Esta categoría fue definida por Antonio Vilanova en "El peregrino andante en el "Persiles» de Cervantes" (1989, p. 326-409) para referir las narrativas largas que siguen el modelo de la novela bizantina.

${ }^{2}$ El estudio de las normas del arte poético prescriptas por Pinciano en Philosophía Antigua Poética (1596), que será presentado en el próximo párrafo, compone la sección 1.3.2 de mi tesis doctoral. la fábula debe ser "perturbadora y quietadora de los ánimos" (Ep. $5^{\text {a }}$ p. 39). Refiriéndose a los efectos, Pinciano explica que las fábulas épicas y trágicas deben "perturbar y alborotar el ánimo (...) por espanto y conmiseración” y las cómicas y ditirámbicas "por alegría y risa". El saludable efecto de la alteración debe ser la quietación del alma, "porque, después destas perturbaciones, el oyente ha de quedar enseñado en la doctrina de las cosas que quitan la vna y la otra perturbación" (Ep. 5a, p. 54). Pinciano prescribe que la admiración resulta de la hermosura de la ficción y del lenguaje (Ep. $3^{\mathrm{a}}$, p. 213), así como del prodigio, del espanto y de la novedad (Ep. 5a, p.57-58), desde que "no salga de los términos de la semejança a verdad" (Ep. 5a, p. 62). 
El análisis de las Novelas ejemplares seguramente puede confirmar que Cervantes no descuida de las normas del arte poético de su tiempo en su novedosa invención, lo que posiblemente le garantizó la estimación del público y de los hombres de letras de su tiempo, una vez que, como observa Julián Olivares, a partir de Novelas "hay una tremenda proliferación de novelas", una moda literaria que tiene su auge en los veinte años siguientes $y$, con menos intensidad, perdura hasta casi el final del siglo (cf. OLIVARES, 2000, p. 34).

Considerando los probables modelos del novelista, Julián Olivares afirma que Cervantes "asimila y desarrolla las novelle de los escritores italianos que siguieron la pauta establecida por el Decamerón, de Boccaccio, cuyos imitadores se extendieron por toda Europa" (2000, p. 33). Sin embargo, el deber ético del arte de alabar la virtud y vituperar el vicio para enseñar buenas costumbres, como enseña Pinciano (Ep. 8a, 1973, p. 360), posiblemente fue la razón por la cual Cervantes añadió el calificativo ejemplares a sus novelas, a fin de disociarlas de la materia erótica de la tradición italiana. Es posible suponer que, quizás, por el mismo motivo, es que siete de las doce Novelas cervantinas tienen el legítimo enlace matrimonial como signo de final feliz.

Aunque el final con matrimonio constituya el patrón de los géneros narrativos que las Novelas ejemplares mimetizan, como las novelas amorosas de aventuras, las novelas pastoriles y la tragicomedia, podemos observar en las bodas de la colección cervantina particularidades que contribuyen a dar rasgos propios a sus novelas cortas. En este estudio se examinan los distintos desenlaces con matrimonio en las Novelas ejemplares y se observa cómo las Novelas amorosas y ejemplares (1637), de María de Zayas y Sotomayor, imitan y emulan este aspecto del modelo cervantino. El método de análisis será el comparativo, pautado exclusivamente en el exámen de los cuentos.

Considerando los casamientos que señalan el final dichoso de las Novelas ejemplares, se puede notar que hay significativas diferencias en las causas que llevan a los personajes a las nupcias, aspecto que propicia distintas configuraciones a los enlaces.

Posiblemente el matrimonio que introduce más novedades a la colección de narrativas cortas es el diseñado en "La Gitanilla". Al ser solicitada por un noble y rico caballero, la hermosa, aguda y discreta joven gitana no se 
perturba ante el afecto y los ofrecimientos del rico y gallardo mancebo. Le contesta:

A mí ni me mueven promesas, ni me desmoronan dádivas, ni me inclinan sumisiones, ni me espantan finezas enamoradas (...). Sé que las pasiones amorosas en los recién enamorados son como ímpetus indiscretos que hacen salir la voluntad de sus quicios (...). Si alcanza lo que desea, mengua el deseo con la posesión de la cosa deseada, y quizá abriéndose entonces los ojos del entendimiento, se ve ser bien que se aborrezca lo que antes se adoraba (CERVANTES, 1993, p. 105-106).

Después de la prudente ponderación, la voluntariosa gitanilla condiciona su consentimiento a la realización de un noviciado de dos años. Durante este período ella y su pretendiente deberán vivir hermanalmente, junto a la comunidad gitana, de modo que conozcan "las faltas o las virtudes" (1993, p. 124) que tienen, y así tanteen y ponderen lo que será bien que escojan o será justo que desechen (1993, p.124).

De acuerdo con los criterios de Preciosa, el matrimonio sería por $a_{m o r}^{3}$ y por libre elección, algo ajeno a las costumbres católicas y aristocráticas de la España en que vivió Cervantes. La Historia de España (1991) registra que, en el siglo XVI:

En las clases elevadas el papel de la mujer era importantísimo, porque de los enlaces matrimoniales dependían los enlaces de linajes y de posesiones, que llegaban a producir acumulaciones impresionantes de bienes y títulos. También en estos casos el papel de la mujer era pasivo, aceptaban el marido que eligiera la familia (TUÑON DE LARA et al, 1991, p. 246).

Tuñón de Lara añade que "el carácter eclesiástico del

${ }^{3}$ Se utiliza el término "por amor" con la connotación dada por Mariló Vigil al casamiento "por amores", eso es, el enlace hecho por la pareja movida por sus afectos y convicciones, sin la intervención de los padres (cf. 1994, p. 79).

${ }^{4}$ Fechas indicadas por Sílvia Hunold Lara (org.), en la cronología de las Ordenações Filipinas, Livro V (São Paulo: Companhia das Letras, 1999, p. 49). matrimonio se reforzó en el Concilio de Trento [1545-1564] ${ }^{4}$, que prohibió los matrimonios clandestinos, es decir, los realizados sin intervención del párroco" (1991, p. 246). A partir de Trento, entonces, la Iglesia pasa a reglamentar y a registrar los matrimonios, perdiendo la validez las bodas concertadas por palabra, a la vez que se intensifica la importancia de los documentos y de los trámites oficiales que darán legitimidad a los enlaces.

Mariló Vigil, en La vida de las mujeres en los siglos XVI y XVII (1994), advierte que en ese período los matrimonios por amor "eran más un tema literario que una realidad. Porque la cuestión de la dote era prioritaria" (p. 79). Sin embargo, Vigil 
supone que "algunos casos de matrimonios no concertados por la familia debieron darse, puesto que los moralistas ${ }^{5}$ los condenan con cierta regularidad" (1994, p. 80). Entre varios ejemplos, cita al doctor Francisco Escrivá, teólogo de la Compañía de Jesús, que en el manual de educación femenina Discursos de los estados (1613) inquiere y avisa:

¿Qué diré de los que se casan por los rincones, por su antojo, y contra la voluntad de sus padres? (...) ¿qué paz, qué amor, que contento se pueden prometer éstos desta manera casados? La mujer que tiene honra y vergüenza no ha de hablar ni pensar en casarse, si no es cuando, y con quien sus padres fuere bien visto (apud VIGIL, 1994, p. 80).

Vigil señala que "en la condena reiterada de los moralistas de que las jóvenes eligieran marido hay una defensa de la sociedad estamental. Si se casaban por su cuenta no es seguro que lo hicieran dentro de su nivel social" (1994, p. 80). Por este motivo, la censura no iba dirigida solamente a las doncellas, sino también a los jóvenes varones, como lo hace el clérigo Pedro Galindo: "peca mortalmente el hijo que habiendo de casarse no quiere con la mujer que sus padres gustan (...) y el que contra su mandato se casa con mujer indigna de su persona y calidad" (apud VIGIL, 1994, p. 81).

Para comprender la connotación del calificativo "indigno", utilizado por el clérigo al referirse a la elección del cónyuge, son importantes las consideraciones del historiador José Sánchez Lora: "téngase en cuenta que sólo es honroso el matrimonio entre iguales en honra y hacienda, siendo un deshonor casar con alguien que, aunque igual en hacienda, está por debajo en honra; es lo que se llama un matrimonio con persona indigna" (1988, p. 141). Para ilustrar este principio, Sánchez Lora registra lo que dictamina el Fray Enrique Villalobos en Summa de la theología moral y canónica (1622): "y adviértase que para este efecto se llama indigno el que es notablemente desigual, ora sea en la honra, ora sea en la hacienda, ora sea en su mala manera de vivir: de suerte que sea afrenta casarse con él" (apud SÁNCHEZ LORA, 1988, p. 141).

Ante tales prerrogativas morales y socioculturales

${ }^{5}$ Es importante aclarar que Mariló Vigil usa el término "moralistas" para referirse a los autores de los manuales de educación femenina, en su gran mayoría autoridades eclesiásticas. 
prerrogativas del honor que pesaban sobre los miembros de la aristocracia católica. No obstante, la joven mimetiza los preceptos de la conducta de las doncellas de las familias nobles, puesto que es "tan honesta, que en su presencia no osaba alguna gitana, ni vieja ni moza, cantar cantares lascivos" (1993, p. 84). Además, ella valora su "entereza y virginidad", por eso, cuando el joven caballero la solicita por mujer, Preciosa le advierte que "si vos, señor, por sola esta prenda venís, no la habéis de llevar sino atada con las ligaduras de los lazos del matrimonio; que si la virginidad se ha de inclinar, ha de ser a este santo yugo" (1993, p. 106).

Se puede pensar que Preciosa tiene en alta estima su honradez y sus convicciones acerca del matrimonio feliz, por eso impone la condición del noviciado prenupcial a su pretendiente, que es aceptado por su abuela y por el grupo de gitanos. No obstante, don Juan, el gallardo mancebo que la solicita por mujer, pertenece a una familia aristocrática $\mathrm{y}$, al proponerse a desposar a una gitana, se encamina a un matrimonio con persona indigna, a un enlace desigual que afrontaría la honra de su ilustre familia. La gravedad de la elección del caballero justifica, en la trama, las cuidadosas precauciones de don Juan para ocultar de sus padres el verdadero motivo que lo aleja del hogar.

El conflicto proveniente de la desigualdad de los novios se disipa cuando se revela la verdadera identidad de la protagonista. Preciosa no es una gitana, sino doña Constanza de Azevedo y de Meneses, hija del Corregidor de Murcia, caballero del hábito de Calatrava, que fue robada de sus padres en la niñez. Simultáneamente se revela que don Juan es hijo de don Francisco de Cárcamo, caballero del hábito de Santiago, y posee el mismo hábito.

A respecto del pacto prenupcial, la voluntariosa Gitanilla se porta como doncella de ilustre linaje y acomoda su gusto al de sus padres. Estos consienten con el matrimonio que su hija y don Juan pretendían, después de averiguar la igualdad de linaje y fortuna de los novios, de asegurarse de que la joven lo quería. Preciosa justifica su afecto "por haber visto por experiencia su buena condición y honesto trato" (1993, p. 152). Por lo tanto, se entiende que el tiempo del noviciado le permitió conocer y estimar la buena condición de su futuro marido. 
Observando la trama de "La Gitanilla" es posible considerar que tras la perturbadora amenaza a los requisitos del honrado matrimonio, instaurados por la aguda Gitanilla y seguidos por el noble don Juan, una peripecia provoca la quietación de todos los conflictos, al promover el ajuste de las identidades, realineando los individuos a su insigne abolengo. La sorprendente igualdad de la pareja torna verosímil que se celebre el pacto apalabrado, uniendo voluntades individuales por medio del "santo yugo", lo que seguramente causa sorpresa y admiración al lector. Las cualidades de la fábula, como se constata, son cuidadosamente atendidas.

Respecto a la trama, vale notar que, al final, la narrativa pone de relieve que el legítimo matrimonio se celebra con las debidas amonestaciones y con la autorización de los padres de los novios. Al lector cabe advertir que el enlace une por amor y por libre elección a la pareja de enamorados, con el consentimiento de las familias, iguales en honra y fortuna. Ante tales consideraciones se puede afirmar que el novedoso criterio individual para las bodas se armoniza ejemplarmente con las prerrogativas morales y sociales de la España del Seiscientos.

En otras de las Novelas ejemplares también se celebran matrimonios por amor y por libre elección, como en "El amante liberal" y en "La española inglesa", observándose que, como ocurrió en "La Gitanilla", los cónyuges reciben de sus padres, por diferentes motivos y circunstancias, la libertad para elegir a sus consortes. Gozando de tal privilegio, los enamorados eligen al que es dueño de sus afectos. El contexto deja claro que los esposos son iguales en linaje y fortuna, lo que satisface a la principal norma de los pactos matrimoniales de la nobleza católica del período: la igualdad de honra y hacienda, como registra Sánchez Lora. Se puede constatar que en estas bodas ejemplares las expectativas individuales no afrontan las normas familiares y sociales.

Analizando comparativamente esas novelas es posible observar un elemento que intensifica la semejanza entre los enlaces por amor y por libre elección: el modo como los personajes se enamoran. En las tres parejas de protagonistas el amor surge a consecuencia de la larga convivencia, en que los novios conocen las gracias y virtudes uno del otro. Preciosa y don Juan descubren sus cualidades durante los 
años de noviciado, en "La Gitanilla"; Leonora atestigua el valor y honradez de Ricardo durante los meses del cautiverio entre los moros, en "El amante liberal"; y Ricaredo e Isabela se estiman viviendo largos años como hermanos, en "La española inglesa". Por consiguiente, el enlace matrimonial entre estas tres parejas une individuos que conocen y aprecian el carácter de su cónyuge.

Otros matrimonios de las Novelas ejemplares son motivados por la pasión amorosa que, iniciada con las chispas de una mirada, enciende el fuego del deseo. La inclinación juvenil por los placeres lleva a Rodolfo a secuestrar y violar a Leocadia, en "La fuerza de la sangre"; impulsa a Teodosia a consentir con la unión amorosa requerida por Marco Antonio, en "Las dos doncellas"; así como conduce a la enamorada señora Cornelia a la consumación de la promesa de matrimonio con el duque de Ferrara. En los tres casos las bodas se celebran como desenlace feliz de los trabajos de los personajes femeninos para recuperar su honor. Por ese motivo, es posible considerar que tales bodas configuran el matrimonio de reparación, puesto que su principal finalidad es restituir la honra de las novias y de sus familiares.

Es curiosa la posibilidad de matrimonio que se esboza al final de la décima novela. El desenlace feliz en "La señora Cornelia" cuenta con la colaboración de los españoles don Juan y don Antonio. Por eso el agradecido duque de Ferrara "les ofreció dos primas suyas por mujeres con riquísima dote" (1991, p. 539). Se puede pensar que este enlace sería una especie de premio a los valerosos caballeros. Ante tal oferta, los españoles:

Dijeron que los caballeros de la nación vizcaína por la mayor parte se casaban en su patria; y que no por menosprecio, pues no era posible, sino por cumplir su loable costumbre y la voluntad de sus padres, que ya los debían de tener casados, no aceptaban tan ilustre ofrecimiento (CERVANTES, 1991, p. 539).

De tales palabras se comprende que los valientes vizcaínos rechazan la oferta del duque porque prefieren respetar la autoridad y la tradición familiar. Regresan a España "adonde se casaron con ricas, principales y hermosas mujeres" (1991, p. 539). Tal vez para destacar la índole ejemplar de estos jóvenes españoles, frecuentemente mencionada en esta novela, ellos se muestran tan determinados a respetar y a cumplir las ancestrales costumbres de su tierra respecto al matrimonio. 
${ }^{6}$ El en capítulo "Grandes, títulos, señores de vasallos", Salazar Rincón ilustra como la nobleza tradicion a lmente afirmó su superioridad a partir de un ideal de perfección transmitida por la sangre como, por ejemplo, el que sostiene Castillo Bovadilla, en Política para corregidores y señores de vassallos, en tiempo de paz y guerra (1597): "es la nobleza total ocasión de hazer los hombres altiuos, magnánimos, esforçados, liberales, sufridos, y leales... Finalmente, de los nobles siempre se presume qualquier cosa buena y virtuosa, y por el contrario... no se presume que los nobles hagan trayción alguna" (apud SALAZAR RINCÓN, 1985, p. 72-73).
La clase de casamiento elegida por don Juan y don Antonio, el decidido y pactado exclusivamente por los padres, también ocurre en "La ilustre fregona", en un contexto bastante distinto. Merece atención que la fregona, aunque dé nombre a la novela, no actúa en la trama ni opina acerca de su boda. En esta novela, el desenlace con tres matrimonios resulta del encuentro de "caballeros ancianos de venerable presencia" (1991, p. 452), iguales en honra y fortuna, que estrechan su parentesco y amistad casando a sus hijos entre sí. Nótese que dos parejas ni siquiera se conocen. Aun así, "quedaron todos contentos, alegres y satisfechos" (1991, p. 460), dice el narrador. Es posible suponer que, en esta novela, el regocijo con los honrados matrimonios entre iguales se debe a que los personajes de ilustre sangre, por medio del enlace nupcial, vuelven a ocupar el lugar de gente distinguida que habían abandonado por diferentes motivos, tanto la fregona ilustre, como los nobles muchachos de pícaras inclinaciones.

El desenlace con múltiples matrimonios decididos por los padres en "La ilustre fregona" parece destinado a señalar la ejemplar restauración de la autoridad familiar, que es aceptada por los jóvenes sin protestas. Además, se puede decir que el final con matrimonio reordena las distorsiones que las impulsivas pasiones juveniles provocaron, tanto en don Diego de Carriazo, padre de la hermosa fregona, fruto de una violación perpetrada por él, que ahora reconduce a su hija ilegítima al seno de la sociedad aristocrática; como en los muchachos, el joven don Diego de Carriazo y don Tomás de Avedaño, que se alejaron de su familia diciendo que iban a estudiar en Salamanca, pero torcieron el camino hacia Toledo, para allí gozar de una vida libre.

El reordenamiento de los ímpetus juveniles hacia la conducta ejemplar que deben demostrar los de noble nacimiento ${ }^{6}$ es particularmente destacada por el hecho de que los tres hijos del joven Diego de Carriazo "hoy están todos estudiando en Salamanca" (1991, p. 460). Es posible imaginar que, después del matrimonio, él ajustó su conducta de modo que se tornó un hombre ejemplar, cuyos hijos no siguieron las censurables inclinaciones del padre y del abuelo.

A respecto del final en apariencia feliz para todas las partes en "La ilustre fregona", cabe señalar que Ruth Fine, en "Relaciones peligrosas: en torno al incesto y la violación en la 
${ }^{7}$ Esta hipótesis resulta de la observación de muchas semejanzas entre los elementos compositivos de los cuentos cervantinos y las características del género novela amorosa de aventura definidas por Antonio Vilanova en el capítulo "El peregrino andante en el 'Persiles' de Cervantes", que, de modo general, son sintetizadas en: "el cúmulo de episodios maravillosos, de lances inverosímiles, $\mathrm{n}$ a v e g a c i o n e s, $\mathrm{t}$ e $\mathrm{mpes} \mathrm{t}$ a d e $\mathrm{s}$, naufragios, raptos, prodigios y muertes fingidas, desemboca en el castigo de los malos, el triunfo de los buenos y la unión definitiva de los dos amantes" (1989, p. 353). Para ilustrar las bodas por compensación en este género de novela se puede tomar como ejemplo el desenlace del Persiles, en que la pareja de protagonistas, tras largos trabajos, logra el legítimo matrimonio. A Arnaldo, que mucho tiempo amó a Sigismunda, "le ofrecieron a la infanta Eusebia para su esposa, hermana de Sigismunda, a quien él acetó de buena gana" (CERVANTES, 1997, p. 727). Se puede decir que este matrimonio compensa al príncipe Arnaldo por el afecto dedicado a Sigismunda.

8 Entre tantos ejemplos se puede citar el desenlace de La dama boba (1613), de Lope de Vega. Allí las nobles hermanas Finea y Nise se casan con nobles caballeros, Laurencio y Liseo. A su vez, las criadas de las damas, Clara y Celia, son dadas como esposas a los criados de los caballeros, Pedro y Turín. Como recurso humorístico se emparejan incluso los dos galanes que quedan sin casar al final de la comedia, Feniso y Duardo (2002, p. 185). obra de Cervantes", al analizar la violencia sexual en "La ilustre fregona" y en "La fuerza de la sangre", sostiene que Cervantes censura la práctica de la violación en sus Novelas Ejemplares al denunciar "el acallamiento impuesto por una sociedad enferma de hipocresía" (2014, p. 199). Fine observa que no hay una reprensión clara a los violadores en la narrativa, pero al publicar la impunidad acerca de la violencia sexual contra la mujer, Cervantes expone al violador "a pleno sol, para que lo juzguemos nosotros" (2014, p. 200). Por lo tanto, el final feliz para todos, proporcionado por el legítimo matrimonio y la generación de honrada descendencia, en ambas novelas, debe suscitar la prudente reflexión del lector.

Además de los matrimonios por amor y por elección, los enlaces de reparación y los decididos por los padres, hay otra clase de boda en las Novelas ejemplares que merece atención. Llama la atención la unión entre Halima y Mahamut, en “El amante liberal", algo completamente inesperado en la trama. Es justo considerar que esta boda no se realiza por amor, sino por compensación, como el propio texto lo deja claro: al no poder "verse esposa de Ricardo", Halima "se contentó con serlo de Mahamut" (1993, p. 205).

El súbito matrimonio católico de los moriscos parece amplificar el modelo de felicidad alcanzado por los loables Ricardo y Leonora, a la vez que da unidad a la trama. El anhelo de felicidad amorosa de Halima, personaje secundario, encuentra un buen fin en el legítimo matrimonio, así como los protagonistas, aunque ella no se case con el varón pretendido. Semejante desenlace ocurre en "Las dos doncellas". La valiente Leocadia ve frustrada su esperanza de casarse con Marco Antonio y, en compensación, acepta el pedido de matrimonio de don Rafael, hermano de su opositora. Vale observar que este tipo de enlace atiende a las fórmulas literarias del género novela amorosa de aventura, que ambas narrativas cortas aparentemente imitan ${ }^{7}$.

De modo particular parece amplificar el desenlace feliz con matrimonio la boda de Sulpicia y Fabio, criados de la rica y noble pareja de protagonistas de "La señora Cornelia". Este matrimonio, no anunciado en la trama antes del desenlace, parece cumplir con la fórmula del colofón de las tragicomedias: múltiples bodas, de amos y criados, siempre respetando la igualdad de estamento de los novios ${ }^{8}$. 
A partir del análisis presentado, es posible afirmar que las diferentes configuraciones que el matrimonio adquiere como signo de desenlace feliz en las Novelas ejemplares dan variedad a la materia amorosa, a la vez que indican la diversidad de los modelos utilizados por el ingenioso Cervantes.

En cuanto a los patrones sociales, es importante considerar que el matrimonio concertado por los padres, sin la consulta o consentimiento de los hijos, era la norma en la España del siglo XVII, como registran Mariló Vigil y Sánchez Lora, a partir de sus fuentes documentales. Sería, por lo tanto, la versión más realista. No obstante, las bodas por amor y por elección que dan el colofón de oro a muchas de las Novelas ejemplares acomodan admirablemente las expectativas individuales y las exigencias del grupo social, sobre todo respecto a la igualdad de linaje, fortuna y fe. Se puede considerar que esta armoniosa compatibilidad trae verosimilitud a la composición poética, asegura el deleite y el provecho a las narrativas y, en consecuencia, garantiza su ejemplaridad. Además, indica cómo Cervantes usa con prudente libertad la doctrina de la imitación y la originalidad, según observa Riley (1981, p. 105-107).

Como primer autor a "novelar" en lengua castellana, el manco de Lepanto inaugura el género y la moda de la novela corta española. Olivares registra que las Novelas ejemplares de Cervantes inician una moda literaria que se extiende casi hasta el final del siglo (2000, p. 34), como ya se ha mencionado. Partícipe de la escuela cervantina, María de Zayas y Sotomayor publica la colección Novelas amorosas y ejemplares en 1637. En el prólogo se enorgullece de ser una mujer que tiene "despejo no sólo para escribir un libro, sino para darle a la estampa, que es el crisol donde se averigua la pureza de los ingenios" (2000, p. 159). La aguda madrileña entra en el mundo de los escritores profesionales para marcar presencia de modo innovador. Olivares asegura que "la perspectiva femenina, excluida de la novela tradicional, es la principal aportación original de Zayas a la novela" (2000, p. 36).

La autora prioriza la perspectiva femenina por medio

${ }^{9}$ El análisis de los personajes femeninos de las Novelas amorosas y ejemplares, de María de Zayas, presentado en este estudio forma parte de mi tesis de doctorado. de sus protagonistas, que hablan y actúan demostrando que las mujeres también tienen virtudes intelectuales y morales. Admirables personajes prueban que las mujeres no son todas iguales $y$, como los varones, poseen firmeza en el amor, aptitud para las armas, coraje y, sobre todo, prudencia. ${ }^{9}$ 
${ }_{10}$ Particularmente el Génesis, capítulo 2, versículo 18 "no es bueno que el hombre esté solo; haréle ayuda idónea para él"; y el versículo 24 "dejará el hombre á su padre y madre, y allegarse ha á su mujer, y serán una sola carne" (Antigua versión de Casiodoro de Reina (1569), revisado por Cipriano de Valera (1602). Londres: Trinitarian BibleSociety, s/d, p. 2). San Pablo, en Corintios I, cap. 7, reafirma la conveniencia del matrimonio.

${ }^{11}$ Fray Luis de León actualiza la lección del Génesis: "el fin para que Dios la crió es para ser ayudadora del marido" (LEÓN, 1968, p. 41).

12 Sobre el estatuto de la limpieza de sangre y las desigualdades sociales entre católicos, los dichos "infieles" y conversos, véase el capítulo "Las jerarquías sociales o la acumulación de las desigualdades", en La España del Siglo de Oro, de Bartolomé Bennassar (Barcelona: Crítica, 2001). Acerca de la unión matrimonial entre personas de diferentes credos, Javier Salazar Rincón observa que "el matrimonio (...) debe asegurar, ante todo, que la sangre se perpetúe sin mácula ni menoscabo en los sucesores. Emparentar con gentes de linaje inferior, o con grupos sociales infamados y perseguidos es (...) manchar con un injerto indigno la genealogía de una familia ilustre" (1985, p. 79).
Las protagonistas femeninas de las Novelas amorosas y ejemplares no son relegadas a un segundo plano de la acción, como ocurre en la mayoría de las novelas cervantinas. Por el amor y por la honra ellas se aventuran, cometen errores y buscan solucionarlos. Gran parte de las narrativas de esta colección de Zayas tienen el matrimonio como signo del final feliz, a semejanza del modelo de Cervantes. Sin embargo, la boda adquiere rasgos particulares bajo la pluma de la audaz escritora.

Ser esposa y madre es el destino natural de la mujer, afirman los libros de la Biblia ${ }^{10} \mathrm{e}$ insisten los tratados de los preceptores católicos dedicados a la educación femenina, como Formación de la mujer cristiana (1523), de Juan Luis Vives, y La perfecta casada (1583), de Fray Luis de León, ${ }^{11}$ entre tantos otros herederos y emisarios de sus preceptos. Sin las nupcias y el marido, la mujer española del siglo XVII carece de posición social y de identidad, afirma Mariló Vigil (1994, p. 92).

Como se ha mencionado, para los miembros de la aristocracia el matrimonio es un contrato público que debe obedecer a las normas de su estamento, sobre todo en lo que toca a la igualdad de los novios, a fin de mantener los privilegios y las diferencias sociales, pautados en la riqueza y la hidalguía, en el estatuto de la honra y de la limpieza de sangre..$^{12} \mathrm{El}$ celo de tales condicionantes, explica Sánchez Lora, determina la vigilancia del grupo, especialmente de los padres, sobre los enlaces, para evitar que sus hijas escojan a una persona inferior a ellas en los citados requisitos (cf. 1988, p. 141). Pese al fuerte control familiar y social, las doncellas sueñan en ser servidas amorosamente, como los personajes de las novelas de caballerías y pastoriles, además, reivindican el derecho de elegir el marido, asevera Vigil (cf. 1994, p. 18-91) a partir de las amonestaciones que los autores de los manuales de educación femenina lanzan a este respecto. Por ejemplo, el doctor Juan Escrivá, teólogo de la Compañía de Jesús, en su Discursos de los estados (1613), censura:

Parece a muchos ahora que conviene, que las doncellas que se han de casar, salgan, y anden, y paseen, y sean vistas; para esto se componen y aderezan, y afeitan, y pintan lo mejor que saben y pueden; y hablan y cantan, y danzan, y hacen todo aquello que ha de ser parte para agradar, y aficionar a los que las miran, y desean que las deseen y huelguen de casar con ellas. Abuso pestilencial; introducción del demonio (apud VIGIL, 1994, p. 84). 
Vigil advierte la exageración en la censura de los severos autores. ${ }^{13}$ No obstante, señala que, a partir de esos textos, es coherente imaginar que "para las doncellas respetables había que encontrar el difícil equilibrio entre el encierro y la exhibición" (1994, p. 83), para que pudieran ver y ser vistas, de modo a conocer y dar a conocer las cualidades que importan para el agradable convivio.

Ante tales consideraciones, es posible suponer que en las Novelas ejemplares de Cervantes la Gitanilla personifica la reivindicación de las españolas de principios del Seiscientos para elegir a su marido. Tal vez la condición de gitana, al inicio del cuento, le dé a la joven la osadía necesaria para ser el vocero de las razones y ambiciones femeninas de su tiempo. Como acuerdo prenupcial Preciosa exige de su pretendiente dos años de servicio amoroso, "en el cual tiempo me satisfaré yo de vuestra condición, y vos de la mía; al cabo del cual, si vos os contentáredes de mí, y yo de vos, me entregaré por vuestra esposa" (1993, p. 106-107). Nótese que la petición de la Gitanilla no ofende los principios de honra y castidad, y tiene como fin el legítimo matrimonio.

Merece atención que Preciosa articula una tesis sobre el origen del amor que no consta de las tradicionales doctrinas. Según su planteamiento los novios deben tantear y ponderar la prenda que será bien escoger o será justo desechar, después de que hayan tenido tiempo para mirarla y remirarla "y ver en ella las faltas o las virtudes que tiene" (1993, p. 124). Esta es una proposición novedosa en las letras españolas que las protagonistas de Zayas van a emular.

A partir del análisis de las Novelas amorosas y ejemplares se puede observar que Zayas concibe una tesis del matrimonio feliz por amor y por libre elección que tiene pautas muy semejantes a las enunciadas por la Gitanilla. Parece evidente que la similitud estrecha la vinculación de las novelas de la autora madrileña con el modelo dado por Cervantes.

13 Vigil cita a varios predicadores católicos, autores de manuales de conducta, que interpretan el ensueño femenino respecto al matrimonio en el apartado En busca de marido (p. 78-91), que forma parte del capítulo 1, La doncella (1994).
La tesis se pone de manifiesto en el conjunto de cuentos de las Novelas de Zayas que tienen el matrimonio como signo de desenlace feliz. Como los admirables personajes cervantinos, los de Zayas no confrontan la autoridad paterna para elegir a su consorte. El conflicto tiene como móvil los criterios de la elección. El principal blanco de la censura es la codicia, evidente cuando los padres rechazan a los pretendientes estimados por 
las hijas para favorecer a los más ricos y de más elevado rango. Tal conflicto es vivido por Aminta (Nov. II), comprometida con su primo por decisión de su tío y tutor. El tío encontró en su propio hijo la mejor persona para administrar la considerable herencia de la joven. Ella se fuga para unirse con quien había escogido. Igual conflicto vive Leonor (Nov. VIII), cuyos padres refutan a su amado don Rodrigo, porque es un segundo, y aceptan a don Alonso, dotado con un hábito de las órdenes militares, pero Leonor es dada como muerta antes de que la boda se consume. También los padres de Estela (Nov. IX) rehúsan el pedido del joven que la hija estima para darla como esposa a un conde italiano. Estela se fuga para no tener que cumplir con el compromiso firmado por los padres.

El engaño y la codicia son el origen del conflicto en las bodas de las virtuosas doña Clara (Nov. VI) y Constanza (Nov. $X)$. El padre de doña Clara ofrece una falsa dote que despierta la codicia de su yerno. Cuando el fraude se revela, el marido pasa a desdeñar y a maltratar a su esposa. En el caso de Constanza, el pretendiente finge estar enfermo de muerte y le pide, como último deseo, la mano de Constanza a su madre, prometiendo dotarla con su gran fortuna. La señora, compadecida, sin ignorar la dote, se la concede. Pocos días después de la celebración el marido recobra la salud y confiesa que la fortuna no existe. En conformidad con su índole, las protagonistas aceptan pacientemente los hechos y son esposas dedicadas.

En las Novelas de Zayas también son objeto de censura las bodas realizadas para remediar las urgencias del amor erótico, como ocurre en el primer matrimonio de Jacinta (Nov. I), de Aminta (Nov. II) y de doña Juana (Nov. VI). El final desafortunado indica la ineficacia de este criterio para la unión dichosa.

Los numerosos matrimonios malogrados movidos por la codicia y la pasión erótica en las Novelas amorosas y ejemplares permiten pensar que señalar los errores que llevan al enlace constituye la primera parte de la lección de Zayas sobre la felicidad conyugal. El fracaso tiene la probable finalidad de producir el desengaño sobre las tradicionales fórmulas para el enlace matrimonial.

Es posible observar que en las Novelas de Zayas la tesis fundamenta tales constataciones fue desarrollado en mi tesis doctoral. 
15 Acerca de la organización de la lección estoica, véase la Tabla de Cebes (Anónimo). Trad. ed. Paloma Ortiz García. Madrid, Gredos, 1995.

${ }^{16}$ Es importante señalar que Constanza (Nov. X) configura una excepcional variante en elconjunto deejemplares p rot a gon is t a s femeninas, pues tras las muchas adversidades conoce mejor el carácter de su marido y mantiene firmemente la decisión de seguir casada con su primero y legítimo esposo. lo que parecía ser un bien, en verdad es un mal, pasan por un período de sufrimiento, en el cual encuentran muchos obstáculos e infortunios. En esta fase las falsas opiniones deben de ser purgadas. El alma debe libertarse de la ignorancia y de la insensatez. Después de librarse de las opiniones equivocadas y de las pasiones, las protagonistas femeninas deben llegar a la moderación de los afectos, lo que les permitirá discernir qué es verdaderamente bueno ${ }^{15}$.

En la trama de las Novelas amorosas y ejemplares causas involuntarias, como ser abandonada por el prometido marido, y acciones impulsivas, como la fuga o el matrimonio secreto, serán la fuente de los muchos trabajos de las protagonistas femeninas. Pero, al final de este período de purgación, ellas estarán libres de las primeras bodas, firmadas por los padres o pactadas por palabra bajo la influencia del fuego amoroso.

Como Cervantes, Zayas está atenta a la verosimilitud. El matrimonio tratado por palabra se revoca del mismo modo, por palabra, o por el abandono del falso amante. La anulación de las primeras nupcias oficiales ocurre por medio de la viudez o por la anulación legal de las bodas no consumadas. Liberadas del indeseado yugo, algunas protagonistas optan por la vida religiosa, otras, por el segundo matrimonio, que ocurre en conformidad con las prerrogativas legales de la unión legítima.

Durante la fase de trabajos y adversidades las protagonistas conocen a hombres valerosos que las ayudan a superar las penas, como ocurre con Aminta (Nov. II) y doña Hipólita (Nov. VII), o conocen mejor el carácter de sus primeros pretendientes, como sucede con doña Clara (Nov. VI), Leonor (Nov. VIII) y Estela (Nov. IX). ${ }^{16}$

Libres de las impulsivas pasiones, guiadas por la razón y la moderación, ellas optan por nuevas bodas. Doña Hipólita es la que expresa detalladamente los motivos de su decisión. Ella convivió un año con don García, período en que el caballero conoció las faltas de la dama, se mostró comprensivo y solidario, prestándole auxilio financiero y emocional. Además, intercedió para que los graves conflictos familiares y pendencias legales de la señora fueran debidamente solucionados. Ante tantas comprobadas cualidades, al quedarse viuda, doña Hipólita "obligada del amor que sabía que la tenía (...), agradada de su talle y satisfecha de su entendimiento, cierta de su nobleza y segura de que estimaría 
su persona, se casó con él, haciéndole señor de su belleza y de su gruesa hacienda" (ZAYAS, 2000, p. 444).

Es importante considerar que el segundo marido de doña Hipólita conoce sus errores y estima sus cualidades. Lo mismo ocurre con el segundo marido de Aminta (Nov. II), que le ayudó a vengar la ofensa a su honor. De modo general, se puede afirmar que los criterios para las segundas nupcias enunciados por doña Hipólita son extensivos a los demás cuentos, con la variante de que doña Clara (Nov. VI), doña Leonor (Nov. VIII) y Estela (Nov. IX) no cometen faltas contra la honra, como hizo doña Hipólita, tampoco las sufren, como ocurre con Aminta. Por lo tanto, en estas tramas el largo convivio da al segundo marido la oportunidad de conocer y estimar las muchas virtudes de su esposa.

Como en "La Gitanilla", en las cinco protagonistas que optan por las segundas bodas solo toman esta decisión tras el convivio fraterno con el elegido por un largo periodo, una especie de noviciado, aunque no intencionadamente establecido. La larga convivencia les permite tantear y ponderar la prenda que juzgan por bien escoger, después de haber tenido tiempo para mirarla y remirarla "y ver en ella las faltas o las virtudes que tiene" (1993, p. 124), tal como propone Preciosa. Se entiende que en este tiempo de convivio los novios tuvieron oportunidades suficientes para satisfacerse del carácter y de la conducta del que eligen por cónyuge. La decisión, probablemente, fue tomada "por haber visto por experiencia su buena condición y honesto trato" (1993, p. 152), como declaró Preciosa al justificar su afecto por el que sería su futuro marido.

Es notable que Zayas, al proponer el desenlace feliz con matrimonio por amor, imita del modelo cervantino la importancia dada a la decisión femenina respecto a la decisión de casarse y a la elección del marido, beneficio que disfruta la protagonista de "La Gitanilla" tanto en la condición de gitana como en la de hija de una familia ilustre y afortunada.

Vale resaltar que si María de Zayas mimetiza los criterios nupciales formulados por Preciosa, en "La Gitanilla", sorprende al introducir variaciones, como el hecho de que tales requisitos se concretan en las segundas bodas, además, en sus Novelas los enlaces por amor y por elección no ocurren entre parejas iguales en títulos y en fortuna. En el final feliz con casamiento 
Zayas, de modo innovador, prescinde del criterio de la igualdad entre los novios, señalando cuidadosamente que las conocidas virtudes y buenas costumbres suplen la falta o la humildad del linaje y de los bienes.

Tras el análisis de la primera colección de cuentos de María de Zayas es posible afirmar que las segundas nupcias de las protagonistas de las Novelas amorosas y ejemplares, llevadas a cabo tras prolongada convivencia, en que los novios conocieron las faltas, estimaron las cualidades uno del otro y superaron juntos grandes dificultades, configuran el colofón de oro de muchas tramas, a la vez que plasman la tesis del matrimonio feliz por amor y por libre elección.

Es importante considerar que las tramas en que se puede reconocer los elementos que conforman la tesis del matrimonio feliz por amor y por elección en las Novelas de Zayas parecen ocupar el lugar de otras categorías de matrimonio identificadas en las Novelas ejemplares de Cervantes, como el matrimonio de reparación y el matrimonio por compensación. En Zayas tampoco hay desenlaces con múltiples bodas, probablemente para dar relieve a los criterios y al resultado de la decisión de los personajes femeninos.

A través del ejemplo dado por las admirables protagonistas de sus Novelas, es posible afirmar que Zayas plantea el enlace matrimonial que no desautoriza a los padres ni ofende las costumbres cristianas y aristocráticas, pero que tiene en alta consideración el carácter y la voluntad de los individuos, más que su igualdad de fortuna y títulos. Se puede evaluar que su propuesta representa un avance moderado y factible que, en algunos contextos, da autonomía a mujeres adineradas y, en otros casos, armoniza de modo verosímil los extremos: la voluntad de las hijas y la expectativa de los padres.

En conformidad con lo expuesto, es posible concluir que es notable la semejanza entre las reivindicaciones femeninas expresas en "La Gitanilla" y la tesis concebida por Zayas para el matrimonio feliz. Con sus audaces protagonistas Zayas amplifica la demanda de Preciosa y graba, en las letras del Siglo de Oro, una significativa y admirable lección sobre los requisitos para un casamiento afortunado.

Por fin, el estudio comparado de las colecciones permite indicar que la voz de la Gitanilla, personaje de las 
Novelas Ejemplares de Cervantes, es emulada en la acción de las protagonistas de Zayas. Al emular al maestro Miguel de Cervantes, la autora ilustra su agudo ingenio, capaz de armonizar artísticamente la ciencia de novelar con la conciencia sobre las reivindicaciones femeninas de su tiempo ${ }^{17}$.

\section{OBRAS CITADAS}

ARISTÓTELES. Poética. Traducción, introducción y notas de Alicia Villar Lecumberri. 3. reimp. Madrid: Alianza, 2009.

CERVANTES, M. de. Novelas Ejemplares. Ed. Florencio Sevilla Arroyo; Antonio Rey Hazas. 30. ed. Madrid: Espasa Calpe, 1993, v 1.

Novelas Ejemplares. Ed. Florencio Sevilla Arroyo; Antonio Rey Hazas. 28. ed. Madrid: Espasa Calpe, 1991, v 2.

Los trabajos de Persiles y Sigismunda. Ed. Carlos Romero Muñoz. Madrid: Cátedra, 1997.

FINE, R. Relaciones peligrosas: en torno al incesto y la violación en la obra de Cervantes. In: MARTÍNEZ MATA, E.; FERNÁNDEZ FERREIRO, M. (ed.). Comentarios a Cervantes. Actas selectas del VIII Congreso Internacional de la Asociación de Cervantistas (Oviedo, 2012). Asturias: Fundación María Cristina Masaveu Peterson, 2014, p.188- 201.

LEÓN, F. L. de. La perfecta casada. 9. ed. Madrid: EspasaCalpe, 1968.

LÓPEZ PINCIANO. Philosophía Antigua Poética. Ed. Alfredo Carballo Picazo. Madrid: Instituto Miguel de Cervantes, 1973, 2v.

OLIVARES, J. Introducción, edición y notas. En ZAYAS Y SOTOMAYOR, María de. Novelas amorosas y ejemplares. Madrid: Cátedra, 2000.

RILEY, E. C. Teoría de la novela en Cervantes. 3. ed. Madrid: Taurus, 1981.

17 Peter Cocozzella (1989) ha atribuido a Zayas la virtud de fundar "su arte en el equilibrio entre ciencia y conciencia" (apud OLIVARES, 2000, p.).
SALAZAR RINCÓN, J. El mundo social del Quijote. Madrid: Gredos, 1985.

SÁNCHEZ LORA, J. L. Mujeres, conventos y formas de la religiosidad del Barroco. Madrid: Fundación Universitaria Española, 1988. 
TUÑÓN DE LARA, M; VALDEÓN BARUQUE, J; DOMÍNGUEZ ORTÍZ, A. Historia de España. Barcelona: Labor, 1991.

VEGA, L. La dama boba. Ed. Diego Marín. 23. ed. Madrid: Cátedra, 2002.

VIGIL, M, La vida de las mujeres en los siglos XVI y XVII. 2. ed.. Madrid: Siglo XXI, 1994.

VILANOVA, A. El peregrino andante en el "Persiles" de Cervantes. En: Erasmo y Cervantes. Barcelona: Lumen, 1989: 326-409.

ZAYAS Y SOTOMAYOR, M. de. Novelas amorosas y ejemplares. Ed. Julián Olivares. Madrid: Cátedra, 2000. 


\section{Resumo}

O desfecho de casamento em Novelas, de Miguel de Cervantes: o exemplo de La Gitanilla para o casamento feliz em Novelas, de María de Zayas

Em sete das doze Novelas ejemplares [Novelas exemplares] (1613), de Miguel de Cervantes, uma celebração de casamento representa um final feliz. A superação de diferentes trabalhos e dificuldades leva os personagens ao casamento em mais de um momento do livro. Embora em cada trama, o casamento tenha um significado particular, ele sempre assegura um caráter exemplar ao enredo específico. É digno de nota que o casamento, como signo de desenlace feliz, possui outros matizes em Novelas amorosas y ejemplares [Enchantments of Love], de María de Zayas. O artigo busca analisar e comparar os elementos que tornam o casamento exemplar nas obras dos dois autores. A análise mostra como María de Zayas rejeita algumas práticas encontradas em nas narrativas de Cervantes que estruturam o final feliz com casamento para dar maior autonomia aos cônjuges e reduzir a autoridade parental. O estudo comparativo conclui que Zayas, possivelmente inspirada pelos desejos da Gitanilla em seu Novelas, muda significativamente sua fórmula usual de desfecho com um casamento para propor um conjunto de critérios pré-nupciais que levam as protagonistas femininas a um casamento feliz.

Palavras-chave: Novela; Casamento; Exemplaridade; Desfecho; Convenções. 


\section{Abstract \\ The denouement with a marriage in Novelas by Miguel de Cervantes: The example of $\mathrm{La}$ Gitanilla for a happy marriage in Novelas by María de Zayas}

In seven out of the twelve Novelas ejemplares [Exemplary Novels] (1613) by Miguel de Cervantes, a marriage celebration represents the happy ending. After overcoming different jobs and strife, characters end up by getting married in one or more cases. Although in each involvement, marriage has its particular meaning, it always ensures that the plot is exemplary. It also needs to be emphasized that marriage, as a sign of happy denouement, has other shades in Novelas amorosas y ejemplares [Enchantements of Love] (1637) by María de Zayas. The article aims to analyze and compare the elements that make marriage exemplary in the works by both story tellers. The analysis shows how Maria de Zayas rejects some practices found in Cervantes's tales that structure the happy ending in marriage to provide greater autonomy to spouses and to reduce parental authority. The comparative study concludes that Zayas, possibly inspired by Gitanilla's claims in her Novelas, significantly changes the usual formulas of plot outcome with a wedding to propose a set of prenuptial criteria that lead their exemplary female protagonists to a happy marriage.

Keywords: Short stories; Marriage; Exemplarity; Denouement; Conventions. 